\title{
Anomalías en los arribos de turistas extranjeros y la recaudación fiscal en Quintana Roo, México
}

\author{
Sergio Lagunas Puls* \\ Universidad del Caribe (México)
}

\author{
Alejandro Palafox Muñoz** \\ Universidad de Quintana Roo (México)
}

\begin{abstract}
Resumen: Más allá de análisis enfocados a cifras absolutas o porcentuales en cambios en llegadas de turistas, para algunos de gran importancia y para otros no, acontecidos en el transcurso del tiempo, son la razón para el objetivo de este trabajo, desarrollando mediciones para identificar la presencia de cambios que puedan ser considerados como estadísticamente significativos. Los resultados muestran que, lejos de esperarse en disminuciones causadas por el huracán Wilma o la contingencia por H1N1, se presentan aumentos de llegadas, todas, en el año 2016, pero sin incidir en el impuesto al hospedaje.
\end{abstract}

Palabras Clave: Turistas extranjeros; Impuesto al hospedaje; Significancia; Arribos de turistas; Quintana Roo.

\section{Singularities in foreign tourist arrivals and tax collection in Quintana Roo, Mexico}

Abstract: Beyond analysis focused on absolute figures or percentage on changes in tourist arrivals, for some of great importance and for others not, occurred in the course of time, are the reason for the objective of this work, developing measurements to identify the presence of changes that can be considered as statistically significant. The results show that, far from the expected, decreases caused by Hurricane Wilma or the H1N1 contingency, they showed more arrivals, all of them, in 2016 but without affecting the lodging tax.

Keywords: Foreign tourists; Lodging tax; Significance; Tourist arrivals; Quintana Roo.

\section{Introducción}

El turismo en el mundo se ha colocado como uuna actividad económica que estimula el crecimiento económico de los lugares en donde se desarrolla. En este sentido para el año 2018, el turismo contribuyó con el movimiento de 1.7 trillones de dólares, teniendo un crecimiento en todas las regiones del planeta, en donde América Latina incrementó su flujo de turistas en 3\% (OMT, 2019). El turismo para México se ha convertido en una pieza fundamental de su crecimiento económico, en las misma temporada el país recibió 41.4 millones de turistas internacionales quienes representan una derrama económica de 22,509.7 millones de dólares (SECTUR 2018). El estado de Quintana Roo, un año antes contribuyó con el $33.6 \%$ de la captación de divisas por concepto de turismo, por lo que sin duda es una actividad económica de gran valía para la región y el país.

Esta fortaleza se suma a la incidencia positiva que tiene el turismo en el ámbito fiscal, ya que a través del impuesto al hospedaje, que para el año 2017 fue de 1,186.5 millones de pesos mexicanos, suma que de acuerdo con la Secretaría de Turismo (2017: 5) "los recursos recaudados son destinados a la promoción y difusión tur'sitica, así como para mejorar la infraetructura turística [...] para Quintana Roo y Guerrero una tercera parte es para la administración del impuesto y dos terceras partes para fines turísticos".

\footnotetext{
* Universidad del Caribe (México); E-mail: slagunas@ucaribe.edu.mx; https://orcid.org/0000-0002-4126-3603

** Universidad de Quintana Roo (México); E-mail: palafox@uqroo.mx; https://orcid.org/0000-0003-3988-9428
} 
Dada la relevancia del impacto económico en el estado, y mediante la revisión de información de las dependencias de gobierno involucradas, el artículo identifica un comportamiento atípico en los datos relacionados con la llegada de turistas internacionales al estado de Quintana Roo y la recaudación del impuesto al hospedaje, lo que deja entrever que a pesar de que la afluencia de turistas se incremente, la captación de impuestos no se eleva, a lo largo de 17 años, ello genera diversas incógnitas que no serán resueltas en este documento. Para llegar a descubrir el comportamiento singular, se realizaron dos pruebas: Test de Grubs y Test de Dixon.

Finalmente, se pueden inferir dos aspectos delicados, el primero relacionado con la desaparición de los ingresos por concepto de la recuadación del impuesto al hospedaje; y segundo el maquillaje de cifras para reingresar al ranking de los países más visitados en el mundo.

\section{La actividad turística en Quinana Roo, México.}

Una de las características de la globalización es que las acciones derivadas del orden neoliberal repercuten en las economías del mundo. En este sentido, el turismo, sobre todo el de carácter internacional, se ha consolidado como una actividad económica de importancia para las economías subdesarrolladas y desarrolladas, por su impacto en el Producto Interno Bruto (PIB), lo que deriva principalmente en un crecimiento económico por el movimiento de bienes de consumo y la entrada de divisas, es decir, la esencia del modo de producción capitalista. De esta manera, las proyecciones del World Travel and Tourism Council afirman que la participación del turismo en el PIB tendrá un incremento del 4\% en la próxima década (WTTC, 2017).

En este sentido, desde la década de los cincuenta, se estimula que la actividad tuviera un flujo con tendencias al alza, a pesar de las crisis propias del sistema, y por ello el turismo siempre ha demostrado su fortaleza y resistencia (OMT, 2017). En este sentido, los registros indican que hace más de sesenta años, el movimiento de turistas internacionales oscilaba alrededor de 25 millones de visitantes internacionales teniendo un incremento del $1.12 \%$ para la década de los ochenta y del $242 \%$ para el nuevo milenio, alcanzando los 1,235 millones de turistas para el año 2016. Evidentemente, el aumento en los desplazamientos sugiere un alza en la captación de divisas, ya que en los cincuenta se contabilizaron 104,000 millones de dólares americanos y para 1980 se registró un aumento del $475 \%$ alcanzando los 1,220,000 millones en 2016 (OMT, 2017).

Por dicha capacidad de generar riqueza y dar espacio a la acumulación ampliada, es que el turismo adquiere una importancia estratégica en aquellas economías donde los recursos naturales son de alto valor paisajístico, toda vez que bajo el modelo neoliberal, la naturaleza se convierte en mercancía y se transforma en el insumo para el desarrollo de la actividad turística, para convertirse en una categoría primordial de comercio internacional al representar el 7\% de las exportaciones mundiales de bienes y servicios (OMT, 2017). Estos números brindan la certeza a los capitalistas para incrementar los montos de inversión, en este sentido, se creció un 4.5\% con respecto a 2016, llegando a 2,221.0 billones de dólares americanos (WTTC, 2017).

Bajo este precedente, Holden (2006) relaciona al turismo como un impulsor de la apertura en las oportunidades de empleo, un mejor ingreso económico de la venta directa de bienes y servicios a los turistas, crecimiento en el número de ingreso por concepto de impuestos relacionados a la actividad turística, los cuales sirven para acrecentar los programas de gobierno ligados al combate a la pobreza y atención a la salud, beneficio no sólo para la comunidad receptora sino también para el país, así mismo esta actividad tiene apertura en la participación de la mujer en la vida económica. De esta manera, el turismo se ha convertido en un eje de acumulación económica (Palafox-Muñoz, 2013), mediante cuatro formas: a) el turismo como oportunidad de desarrollo y reducción de la pobreza; b) el turismo como beneficiado y generador de mayor pobreza; c) el turismo como posibilidad de empoderamiento colectivo a través de la gestión comunitaria; y d) la pobreza como atractivo (Cañada, 2017).

En México, este efecto se hace notorio desde la década de los sesentas al considerar a la actividad turística una alternativa para el desarrollo en un ambiente de amplios desequilibrios por el incremento del gasto y la baja captación de ingresos (Cárdenas, 1996). En consecuencia, el turismo a partir de los setenta tuvo un crecimiento acelerado ocasionado por la vasta inversión extranjera que funcionó para la financiación del desarrollo económico y social del país" (Jiménez, 1993). Los estados beneficiados fueron Baja California, Sonora, Nayarit, Jalisco, Guerrero y Quintana Roo, en donde el turismo a desarrollar estaba el vinculado a largas estancias de los turistas en las costas mexicanas en espacios con amplia infraestructura de hotelera y extra hotelera, dando inicio a la faceta neoliberal del desarrollo turístico al abandonar la promoción económica a través del turismo que se desarrollaba mediante las empresas públicas (Macedo, 1995). 
Tras la inserción del modelo económico neoliberal en territorio nacional, la orientación de la política turística buscaba fortalecer la competitividad y sustentabilidad de los destinos, así como de sus productos con el propósito de generar un mayor número de plazas de empleo y condiciones de trabajo óptimas, estas acciones estaban alineadas al desarrollo del turismo mundial, con la finalidad de incrementar la rentabilidad dando continuidad al modo de producción capitalista de tipo neoliberal, en donde los organismos internacionales dictan la política económica a seguir, es decir que desde 1953 las acciones del Estado están encaminadas a la captación de turismo norteamericano y la importación de trasnacionales para la creación de nuevos destinos de playa (Palafox \& Alvarado, 2005).

Bajo ese mismo orden de ideas, el estado de Quintana Roo desde hace 16 años ha tenido un crecimiento en el número de turistas y excursionistas que arriban al estado, desde 1999 la entidad ha recibido más de 133 millones de turistas hasta diciembre de 2016, teniendo en promedio la llegada de poco más de 8 millones de extranjeros (Ver Gráfico 1), ya que la cuantificación de los viajeros nacionales es complicada por el gasto que implica la obtención de información, aun cuando el beneficio que permea en otras esferas de la vida económica es de mayor retribución, a diferencia de la concentración de capitales en las empresas trasnacionales por su efecto en el Producto Interno Bruto al recibir moneda extranjera.

Gráfico 1: Turistas y pasajeros de crucero en Quintana Roo 1999 - 2016.

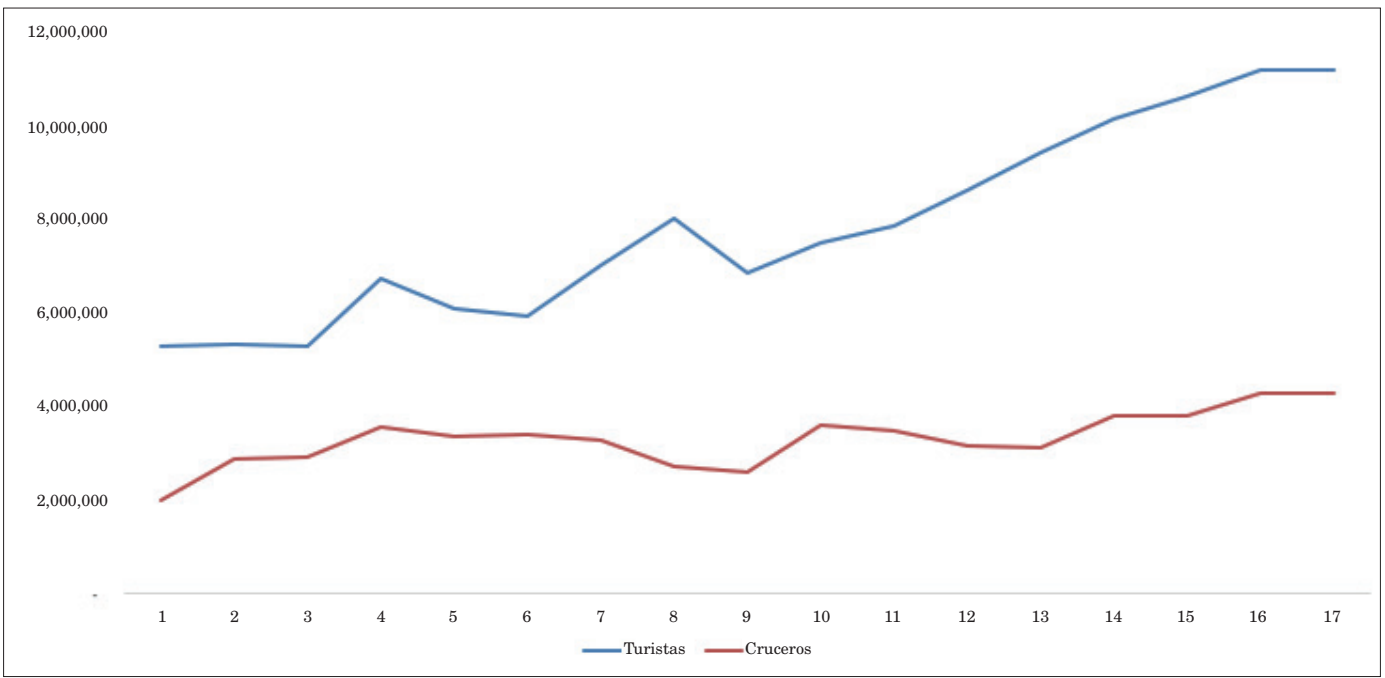

Fuente: Elaboración propia con datos de la Secretaría de Turismo del estado de Quintana Roo.

Los datos indican incrementos constantes en el arribo de turistas, con un alza abrupta en el año 2002, sin embargo, un año después baja menos del $10 \%$ justo después de haber tenido un alza de poco más del $20 \%$. No obstante, para 2005 se presentaron dos fenómenos naturales que impactaron directamente las costas de la entidad, el huracán Emily y el ciclón tropical Wilma, este último afectando de manera considerable la infraestructura de acceso y servicios, así como la oferta turística hotelera y extra hotelera, a pesar de ello no se reportó una reducción en el número de visitantes a los destinos turísticos de Quintana Roo hasta un año después. Para 2009, se recibieron únicamente 6.8 millones de turistas, es decir 15\% menos que el año anterior; situación que puede ser atribuible a la crisis económica de los Estados Unidos, principal mercado turístico de México, lo que marca una clara dependencia de los efectos que puede presentar la escasa diversificación turística del país y la dependencia de un solo mercado emisor.

Posterior a la pérdida de visitantes del año 2009, el crecimiento en las cifras ha ido en aumento año con año, hasta llegar al año 2016 con una cifra récord de 11.18 millones de turistas internacionales en el estado, sin embargo ese éxito no tiene el mismo alcance en el rubro económico, ya que desde el inicio del nuevo milenio se han captado 120,336.78 millones de dólares americanos, de los cuales $91.7 \%$ de los ingresos dependen de dos destinos, Cancún y la Riviera Maya (Ver Gráfico 2). 
Gráfico 2: Derrama económica en destinos de Quintana Roo 2000-2016.

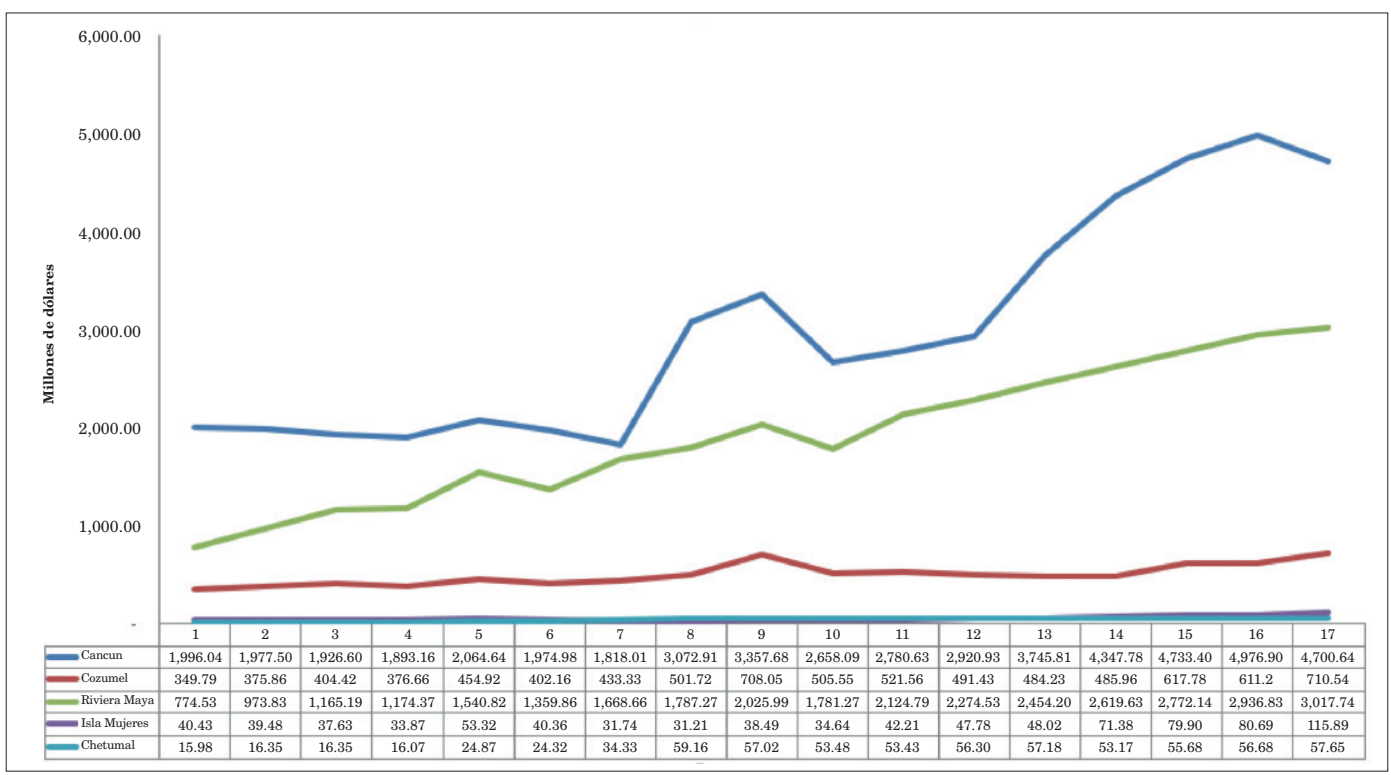

Fuente: Elaboración propia con datos de la Secretaría de Turismo del estado de Quintana Roo.

En lo referente a la derrama económica, los datos permiten inferir e identificar ciertas inconsistencias durante el lapso de tiempo que presentan los datos del Gráfico 2, en el año 2005, de acuerdo con la Secretaría de Turismo del estado de Quintana Roo (SEDETUR), las eventualidades climatológicas (huracanes Wilma y Emily) no provocaron que disminuyera de manera importante la llegada de turistas respecto al año anterior. Sin embargo, la baja fue del 6.8\% y la reducción de los ingresos del 8.1\%, a pesar de que la paridad peso-dólar, que en esas fechas era favorable para México, pero los efectos continuaron resintiéndose un año después de las afectaciones, ya que el estado recibió 9.95 millones de turistas y sólo 3,986.07 millones de dólares, es decir sólo 4.6\% más que en 2005.

A partir del año 2007, se comenzó a dar cierta recuperación logrando alcanzar los 6,187 millones de dólares dos años después, pero iniciaba la crisis económica en EEUU, lo que provocó una reducción en los ingresos del 18.6\% y de 13.1\% en el flujo de visitantes para los años 2009 y 2010. Para el año 2011, la derrama económica y el número de turistas ha venido en aumento, pero a pesar del éxito económico, las repercusiones ambientales y sociales son cuestionables, ejemplo de ello es la inclusión del municipio de Benito Juárez -donde se encuentra Cancún-, el cual está incluido en el Sistema Nacional para la Cruzada contra el Hambre (Secretaría de Gobernación, 2013).

\section{Presiones en la actividad turística de Quintana Roo.}

Existen estudios que, en un esfuerzo por cuantificar los impactos en el turismo originados por diversos factores, ya sean económicos, sociales o ecológicos, entre estos últimos los fenómenos meteorológicos, destaca lo acontecido en Junio y Septiembre con el embate de los huracanes Emily y Wilma, ambos en el año 2005, y se ha llegado a estimar que los daños totales producidos por Wilma fueron por 1,752 millones de dólares (Unión Cancún, 2016), de los cuales el 91.55\% corresponderían a daños en el sector turismo. Lo anterior, constituiría un complicado panorama económico en México, ya que los destinos que registraron mayores daños por el meteoro están al norte del estado de Quintana Roo, afectando principalmente a Cancún perjudicando su derrama turística anual cercana a los 2,000 millones de dólares, con llegadas de turistas y excursionistas cercano a los 3 millones de personas en los años anteriores al 2005. Estudios complementarios a las coberturas de seguros por los daños también del Huracán Wilma, llegaron a catalogarlos como los acontecimientos más caros y complicados en toda la historia de los seguros en México e incluso de Latinoamérica ya que el número de siniestros registrados alcanzó los 15,126 (sin contar reclamos de automóviles) lo que para la Compañía de Seguros Atlas habría significado pérdidas por 1,780 millones de pesos (Sánchez, 2006). La zona norte del estado fue la más 
afectada, los destinos de Cozumel, Puerto Morelos y Cancún fueron la zona de embate del meteoro (Palafox \& Velázquez, 2008), en suma el daño a la infraestructura turística, el medio ambiente, con énfasis en las playas (Mansilla, 2006).

Después de haber sorteado las afectaciones por el embate de Wilma, la actividad turística para México repunta en el año 2008 constituyéndose como la cuarta fuente de divisas del país, sumando 12,901.00 millones de dólares, solo después de la exportación de petróleo, recepción de divisas e inversión extranjera. A pesar de la problemática que presentó el estado de Quintana Roo contribuye con el 33.8\% de las divisas de todo el país por concepto de turismo, mismas son recabadas a través de los destinos de la entidad (SEDETUR, 2008).

Durante los años 2003 a 2006 el turismo representó el 8.5\% del Producto Interno Bruto de México, sin embargo, después de las pérdidas sufridas durante el año 2005, situación que agravó el complicado ambiente económico, debido a la recesión a nivel mundial, sobre todo a partir del segundo semestre del año 2008 y debido a las pérdidas económicas que ocasionaría lo que se denominó en el año 2009, como Contingencia Sanitaria A H1N1. De esta manera, en el primer cuatrimestre del año 2009, el número de trabajadores formales en la industria turística, es decir, aquellos que contaban con prestaciones patronales ante el Instituto Mexicano del Seguro Social (IMSS) disminuiría poco más del 2.5\% respecto al mismo período del año anterior, más aun considerando que disminuiría la demanda de servicios turísticos pues los viajeros, provenientes principalmente de los Estados Unidos de América (EE.UU.) vivían es su propio país una desaceleración económica, lo que derivó en una reducción del tiempo de viajes y limitando su gasto en los sitios visitados (Centro de Estudios de las Finanzas Públicas, 2009).

Sin embargo, aun con los efectos de la recesión económica norteamericana, las eventualidades sanitarias y climatológicas, el número de llegadas de turistas extranjeros que visitaron el estado de Quintana Roo, desde el año 1992 y hasta el año 2016 es por demás significativo por el crecimiento sostenido que presentan los números, lo anterior es claramente evidenciable, incluso difícil de creer, considerando los efectos negativos de Wilma y de la contingencia A H1N1. Con referencia al primer caso se puede afirmar que las llegadas en el mes de noviembre del año 2004 fueron 391,475 y un año después en el mismo mes, la cifra únicamente registró 103,098 (punto rojo de la Gráfico 3) es decir, una disminución del 73.67\% (SECTUR, 2018).

\section{Gráfico 3: Serie de tiempo de las llegadas de turistas extranjeros a Quintana Roo, años1992 - 2016}

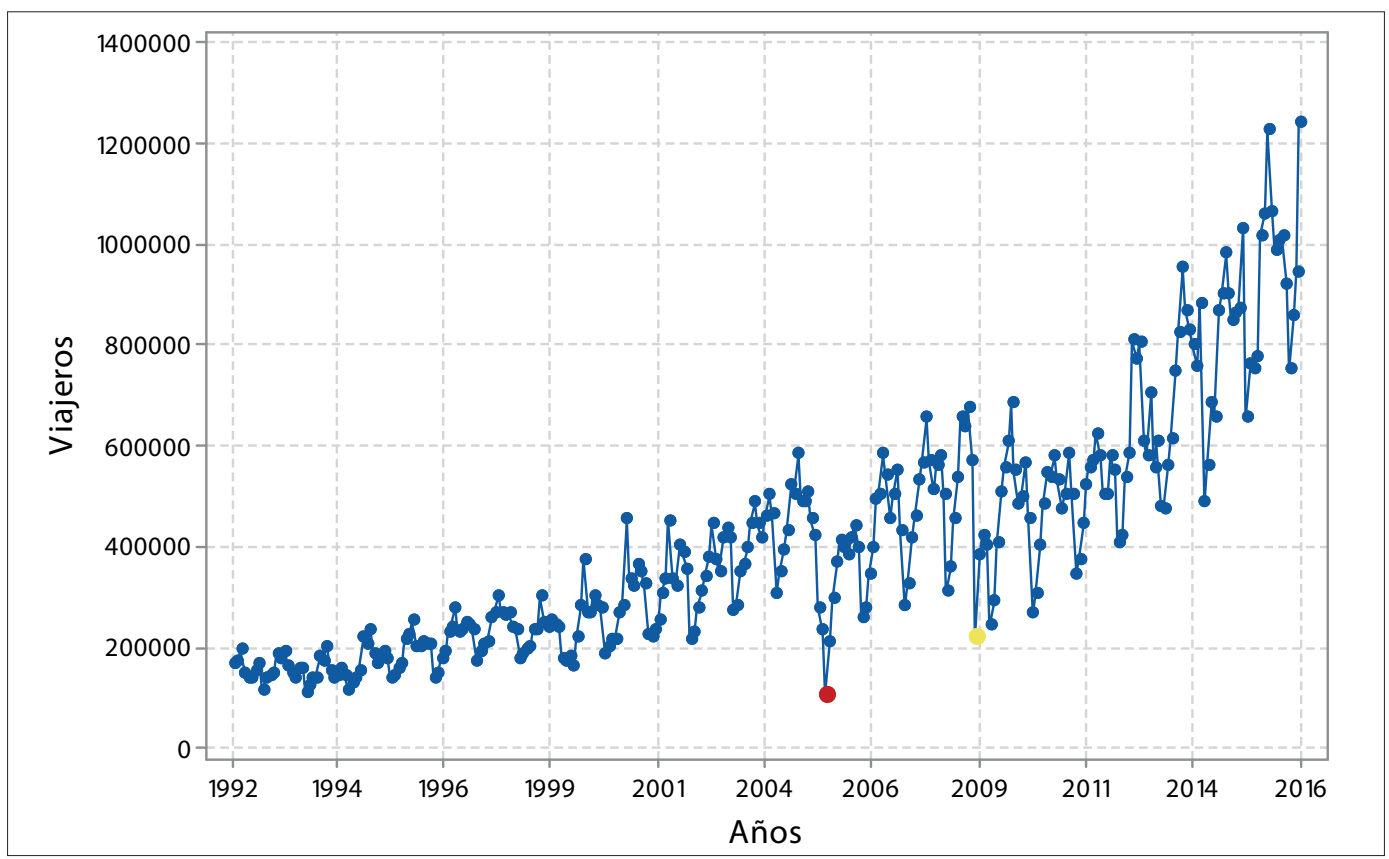

Fuente: Elaboración propia. 
Con respecto a la mayor afectación atribuida a la contingencia sanitaria A H1N1, al comparar las 510,083 llegadas de turistas extranjeros a Quintana Roo en el mes de mayo del año 2008, para ese mismo mes del siguiente año, se registraron únicamente 216,700 llegadas (punto amarillo de la Gráfica 1), lo que significaba una disminución del 41.48\% (SECTUR, 2018).

Posterior a la baja registrada en 2009, el número de llegadas al estado no se ha visto afectada negativamente a esos niveles y tampoco al nivel de los sucedido en 2005, pero las cifras han generado especial interés de investigadores en materia económica y turística, materializando esfuerzos de investigación en informes, estudios y artículos académicos que muestran porcentajes de afectación, valores monetarios de las pérdidas (Jarmin \& Miranda, 2009), número de individuos afectados en la población (Oswald, 2012), sin dejar de mencionar las pérdidas en la industria turística (Centro de Estudios de las Finanzas Públicas, 2009; CEPAL, 2010) y por ende la recaudación fiscal que depende del esta actividad, específicamente lo relacionado con el impuesto al hospedaje.

No obstante, es importante que más allá de las apreciaciones del público interesado en los esutdios económicos y turísticos consideren que, una disminución en la actividad sea grave, medianamente grave, leve o bien de poca significancia, cuando se registre una baja del $40 \%$ en los datos relacionados con la llegada de turistas a un determinado destino disminuyan alrededor de 100,000 visitantes o más, se considera esencial contar con criterios de valoración estadística que, a través de metodologías consolidadas y empleadas en las disciplinas económicas y administrativas permitan aportar elementos que definan sí una determinada reducción en un período de tiempo determinado, respecto a las llegadas de turistas extranjeros o bien en una variable relacionada como la recaudación del impuesto al hospedaje, deba ser considerada estadísticamente atípica o fuera de lo normal aceptando que aún a pesar de los juicios personales se pudiera pensar como grave o quizá estadísticamente no lo sea.

Por lo tanto, en este trabajo se desarrollarán métodos estadísticos tendientes a identificar anomalías estadísticamente graves, que puedan ser consideradas como ocurrencias atípicas y en caso de existir estas singularidades relacionarlas con algún determinado fenómeno, natural o no, que deba ser considerado para estudios posteriores a este primer planteamiento de investigación estadística entre el turismo y la economía.

\section{Nota metodológica}

Considerando que el objetivo general de este trabajo está enfocado a identificar sí el número de llegadas de turistas extranjeros a Quintana Roo se ha visto presionado positiva o negativamente a través del tiempo, se analizan datos correspondientes a 204 informes mensuales, de enero del año 2000 a diciembre del 2016 (SECTUR, 2018). De esta manera, para tener una contrastación con otra variable directamente relacionada, se analizan los datos de la recaudación del impuesto al hospedaje ${ }^{1}$ para el mismo periodo de tiempo (Secretaria de Finanzas y Planeación de Quintana Roo, 2016a; Secretaría de Finanzas y Planeación, 2016b).

Metodológicamente, para tener una descripción estadística del patrón de llegadas e impuesto recaudado, se aplican en las series completas dos pruebas de normalidad, considerando un intervalo de confianza del 95\%. La primera prueba es conocida como el test de Anderson-Darling (AD) con valor crítico de 0.751 (Ang \& Wilson, 2007), la cual se asume como equivalente a que al menos el 95\% de los datos cumplen con la condición antes señalada, si no sobrepasan el valor crítico de 0.751 .

La ecuación para obtener el test AD (Stephens, 1979) es:

$$
A D=-\frac{\left\{\sum_{i=1}^{n}(2 i-1)\left[\ln z_{i}+\ln \left(1-z_{n+1-i}\right)\right]\right\}}{n}-n
$$

Por otra parte, para considerar que el comportamiento de las llegadas y la recaudación es normal por el criterio AD, y para ello deberá cumplirse lo siguiente (Lagunas \& Cervantes, 2020):

$H_{1}:$ Si $A D<0.751$ entonces los arribos se consideran estadisticamente normales

$\mathrm{H}_{2}: \mathrm{Si} A D<0.751$ entonces la recaudación del impuesto es estadísticamente normal

Para identificar si el número de datos que se encuentran más allá del 95\% de confianza, es decir, que superan 1.64 múltiplos de desviación estándar, ya sean en extremo mayores al promedio o menores 
(análisis de dos colas), estos no deberán superar entre los dos extremos. Por lo que se requiere de realizar el test p-valor, pero esta prueba requiere de estimar la media $(\mu)$, la desviación estándar $(\sigma)$ y la varianza $\left(\sigma^{2}\right)$, lo que permitirá.

$$
\begin{aligned}
& \mu=\frac{\sum_{i=1}^{n} x_{i}}{n} \\
& \sigma^{2}=\frac{\sum_{i=1}^{n}\left(x_{i}-\mu\right)^{2}}{n-1} \\
& \sigma=\sqrt{\sigma^{2}}
\end{aligned}
$$

De esta manera, para considerar que el comportamiento de las llegadas y la recaudación es normal mediante el criterio de p-valor, deberá cumplirse lo siguiente:

$H_{3}:$ Si,p valor $>0.05$ entonces los arribos de turistas se consideran estadisticamente normales

$H_{4}:$ Si,p valor $>0.05$ entonces la recaudación del impuesto es estadisticamente normal

Identificación de valores atípicos en agrupaciones mensuales.

Después de realizar las pruebas de normalidad para las series completas, se agrupará la información mensualmente de las llegadas de turistas extranjeros y la recaudación fiscal, en el periodo comprendido de los años 2000. Al contar con las series de datos integradas por mes, se espera identificar la existencia de datos anómalos que pudieran coincidir con alguna presión externa que provoque mayores o menores llegadas y/o recaudación fiscal.

Para lograr lo anterior se realizarán las estimaciones mediante el test de Grubbs (Grubbs, 1969; Beck \& Grubbs, 1972), el cual ha sido ampliamente utilizado para identificar datos atípicos en diversas variables económicas, financieras, sociales e inclusive del sector salud (Dan \& Ijeima, 2013; Solak, 2009; Urvoy \& Autrusseau, 2014; Siekelova, Kliestik, Svabova, Androniceanu \& Schonfeld, 2017), ya que en todos los casos, el test de Grubbs $(G)$ ha demostrado ser eficaz en la detección de valores anómalos para una sola variable.

Para estimar G, se debe identificar el valor más grande o más pequeño de cada serie, y elegir de entre estos dos datos aquel que se encuentre más alejado del promedio, de esta manera se tiene que:

$$
G=\max \left|\frac{\bar{y}-y_{1}}{s}, \frac{y_{2}-\bar{y}}{s}\right|
$$

En donde:

$y=$ media

$s=$ desviación estándar

$y_{1}=$ dato menor de la serie

$y_{2}=$ dato mayor de la serie

De las series de datos (llegadas de turistas o recaudación de impuesto), de acuerdo a la fórmula (5), se seleccionará el dato que sea mayor tomando en cuenta su valor absoluto, el resultado será comparado con la tabla de valores críticos para G con significancia ( $\alpha=0.05$ (Grubbs, 1969). Se tomarán en consideración 17 datos equivalentes al número de meses en los años observados durante el periodo de 2000 a 2016, por lo que el nivel de significancia para G será 2.47, a saber:

\section{$\mathrm{H}_{3}$ : Si $\mathrm{G} \leq 2.47$ entonces los arribos de turistas no presentan dato atípico o anómalo \\ $H_{4}: S i, G \leq 2.47$ entonces la recaudación del impuesto no presenta dato atípico o anómalo}


Para fortalecer las pruebas que detectan los valores atípicos, se utilizó el test de Dixon (Q), el cual será determinado al ordenar de manera ascendente los datos de cada uno de los meses/años. Con las cifras así dispuestos, se aplicará lo siguiente (Böhrer, 2008):

$$
Q_{i j}=\max \left|\frac{y_{i+1}-y_{1}}{y_{n-j}-y_{1}}, \frac{y_{n}-y_{n-i}}{y_{n}-y_{j+1}}\right|, i=1,2 ; j=0,1,2
$$

En donde:

$$
\begin{aligned}
& y_{1}=\text { dato menor } \\
& y_{n}=\text { dato mayor } \\
& y_{i}=\text { dato a evaluar }
\end{aligned}
$$

Se considera para Q un nivel de confianza del 95\%, con el propósito de que la significancia sea $\alpha=0.05$ observando la tabla de valores críticos (Dixon 1951; Böhrer, 2008) para 17 observaciones que equivalen a 0.320 , por lo tanto:

$$
\begin{aligned}
& H_{3}: S i Q \leq 0.320 \text { entonces los arribos de turistas no presentan dato atípico o anómalo } \\
& H_{4}: S i, Q \leq 0.320 \text { entonces la recaudación del impuesto no presenta dato atípico o anómalo }
\end{aligned}
$$

\section{Anomalías entre la recaudación del impuesto al hospedaje y el arribo de turistas extranjeros}

En las pruebas de normalidad relativas a las llegadas de turistas extranjeros y la recaudación del impuesto al hospedaje resultaron en un rechazo a las hipótesis $H_{1}, H_{2}$, ya que los datos analizados están conformados por 204 observaciones mensuales para cada variable, así lo demostraron las series que no pueden ser consideradas estadísticamente normales, los resultados están incluidos en la Tabla 1.

Tabla 1: Resultados a las pruebas de normalidad para las series de datos completas.

\begin{tabular}{|l|c|c|c|c|}
\hline \multicolumn{1}{|c|}{ Variable } & $\begin{array}{c}\text { Test Anderson - } \\
\text { Darling (AD) con } \\
\text { valor crítico de } \\
\mathbf{0 . 7 5 1}\end{array}$ & $\begin{array}{c}\text { Aceptación } \\
\text { / rechazo de } \\
\text { hipótesis }\end{array}$ & $\begin{array}{c}\text { Test p-valor con } \\
\text { valor crítico de } \\
\mathbf{0 . 0 5}\end{array}$ & $\begin{array}{c}\text { Aceptación } \\
\text { / rechazo de } \\
\text { hipótesis }\end{array}$ \\
\hline $\begin{array}{l}\text { Llegadas } \\
\text { de turistas } \\
\text { extranjeros }\end{array}$ & $\mathrm{AD}-4.214$ & $\begin{array}{c}\text { Se rechaza } H_{1} \\
\text { debido a que } \\
A D>0.751\end{array}$ & $p$ valor $<0.05$ & $\begin{array}{c}\text { Se rechaza } H_{3} \\
\text { debido a que } \\
A D<0.05\end{array}$ \\
\hline $\begin{array}{l}\text { Recaudación } \\
\text { del impuesto al } \\
\text { hospedaje }\end{array}$ & $\mathrm{AD}-7.384$ & $\begin{array}{c}\text { Se rechaza } H_{2} \\
\text { debido a que } \\
A D>0.751\end{array}$ & $p$ valor $<0.05$ & $\begin{array}{c}\text { Se rechaza } H_{4} \\
\text { debido a que } \\
A D<0.05\end{array}$ \\
\hline
\end{tabular}

Fuente: Elaboración propia.

De acuerdo con los resultados contenidos en la Tabla 1, las hipótesis de normalidad, tanto para las llegadas de turistas extranjeros como para la recaudación del impuesto al hospedaje, en ambos casos no pueden considerarse estadísticamente normales de acuerdo a los dos test de normalidad aplicados. Esta situación se aprecia visualmente en la siguiente Gráfica 4, observando que en los extremos de la línea roja, existen varios datos que superan las líneas de normalidad. 


\section{Gráfico 4: Imágenes de la probabilidad evaluada para normalidad}

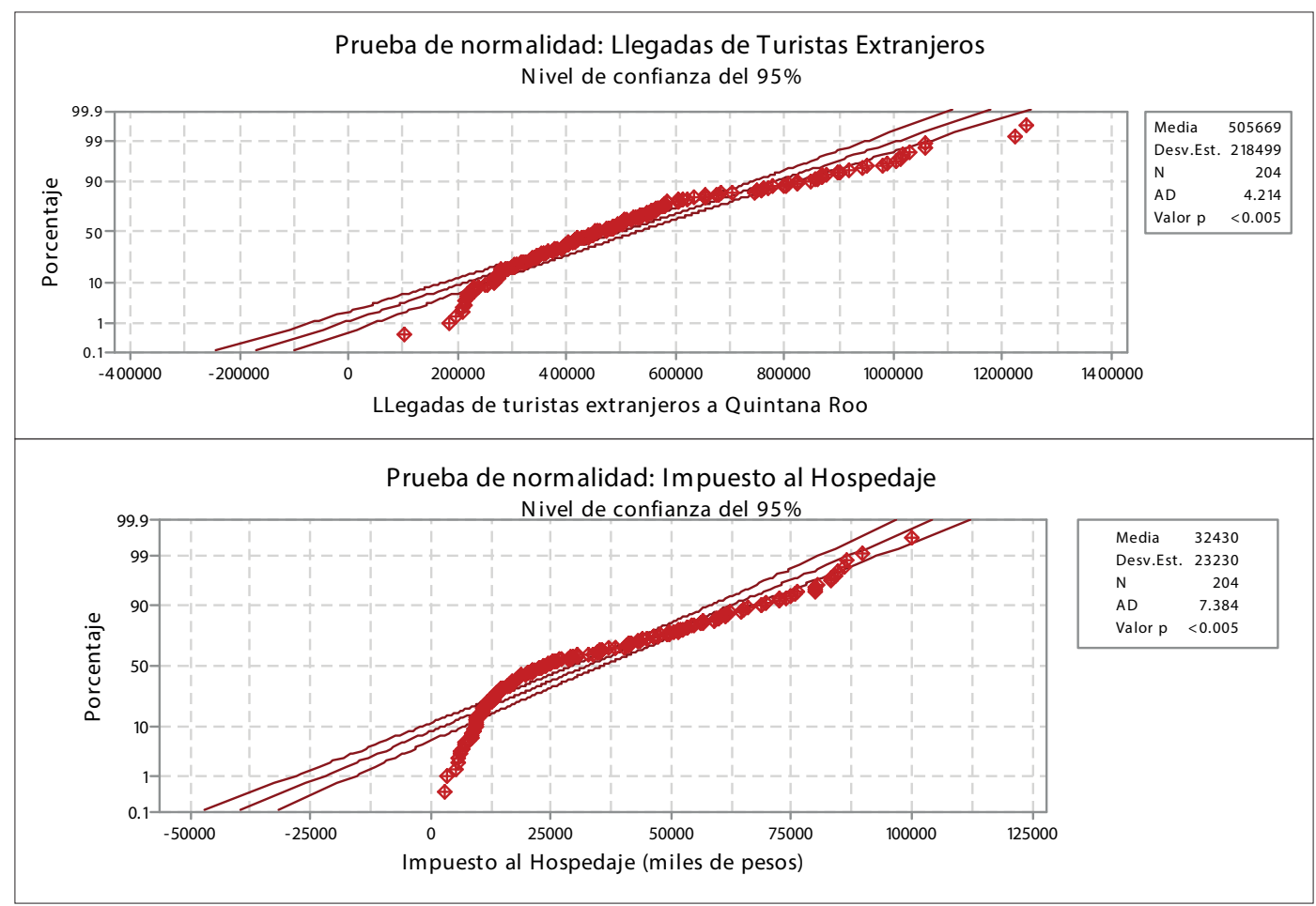

Fuente: Elaboración propia.

Para conocer si los datos más pequeños de cada variable deberían ser considerados como atípicos, la información se agrupó mensualmente para las series de datos de 2000 a 2016, es decir, 17 observaciones para los meses de enero, 17 para los meses de febrero y así sucesivamente hasta los meses de diciembre, los resultados se presentan en la Tabla 2 y Tabla 3.

Conforme a la Tabla 2, las pruebas para conocer si de los valores más pequeños de cada agrupación mensual (17 valores por mes) pueden considerarse como atípicos o fuera de lo normal, se rechazaron las hipótesis, concluyendo que las menores llegadas de turistas registradas en cada mes en 17 años estarían consideradas como normales.

El Gráfico 5 complementa visualmente los resultados numéricos de la Tabla 2, confirmando que en ningún caso que las disminuciones de visitas puedan considerarse fuera de lo normal (atípicas). 
Tabla 2: Identificación de datos atípicos en Llegadas de turistas extranjeros. (Prueba a los valores menores)

\begin{tabular}{|l|c|c|l|c|l|}
\hline $\begin{array}{c}\text { Grupos de } \\
\text { datos por } \\
\text { mes }\end{array}$ & $\begin{array}{c}\text { Valor mínimo de } \\
\text { la serie }\end{array}$ & $\begin{array}{c}\text { G (Grubbs) } \\
\text { Valor critico } \\
\mathbf{G}<\mathbf{2 . 4 7}\end{array}$ & Aceptación / rechazo de hipótesis & $\begin{array}{c}\text { Q (Dixon) } \\
\text { Valor crítico } \\
\mathbf{Q}<\mathbf{0 . 3 2 0}\end{array}$ & $\begin{array}{c}\text { Aceptación } \\
\text { / rechazo de } \\
\text { hipótesis }\end{array}$ \\
\hline Enero & 216,694 & 1.40 & Rechazada. No existe dato atípico & 0.06 & $\begin{array}{l}\text { Rechazada. No } \\
\text { existe dato atípico }\end{array}$ \\
\hline Febrero & 278,290 & 1.28 & Rechazada. No existe dato atípico & $\begin{array}{l}\text { Rechazada. No } \\
\text { existe dato atípico }\end{array}$ \\
\hline Marzo & 372,956 & 1.17 & Rechazada. No existe dato atípico & 0.04 & $\begin{array}{l}\text { Rechazada. No } \\
\text { existe dato atípico }\end{array}$ \\
\hline Abril & 267,617 & 1.33 & Rechazada. No existe dato atípico & 0.08 & $\begin{array}{l}\text { Rechazada. No } \\
\text { existe dato atípico }\end{array}$ \\
\hline Mayo & 216,700 & 1.31 & Rechazada. No existe dato atípico & 0.06 & $\begin{array}{l}\text { Rechazada. No } \\
\text { existe dato atípico }\end{array}$ \\
\hline Junio & 301,277 & 1.23 & Rechazada. No existe dato atípico & 0.08 & $\begin{array}{l}\text { Rechazada. No } \\
\text { existe dato atípico }\end{array}$ \\
\hline Julio & 280,782 & 1.42 & Rechazada. No existe dato atípico & 0.09 & $\begin{array}{l}\text { Rechazada. No } \\
\text { existe dato atípico }\end{array}$ \\
\hline Agosto & 273,966 & 1.15 & Rechazada. No existe dato atípico & 0.07 & $\begin{array}{l}\text { Rechazada. No } \\
\text { existe dato atípico }\end{array}$ \\
\hline Septiembre & 185,499 & 1.03 & Rechazada. No existe dato atípico & 0.04 & $\begin{array}{l}\text { Rechazada. No } \\
\text { existe dato atípico }\end{array}$ \\
\hline Octubre & 198,911 & 0.98 & Rechazada. No existe dato atípico & $\begin{array}{l}\text { Rechazada. No } \\
\text { existe dato atípico }\end{array}$ \\
\hline Noviembre & 103,098 & 1.62 & Rechazada. No existe dato atípico & $\begin{array}{l}\text { Rechazada. No } \\
\text { existe dato atípico }\end{array}$ \\
\hline Diciembre & 209,515 & 1.18 & Rechazada. No existe dato atípico & $\begin{array}{l}\text { Rechazada. No } \\
\text { existe dato atípico }\end{array}$ \\
\hline
\end{tabular}

Fuente: Elaboración propia.

Gráfico 5: Agrupación de valores menores por meses.

Llegadas de turistas extranjeros a Quintana Roo.
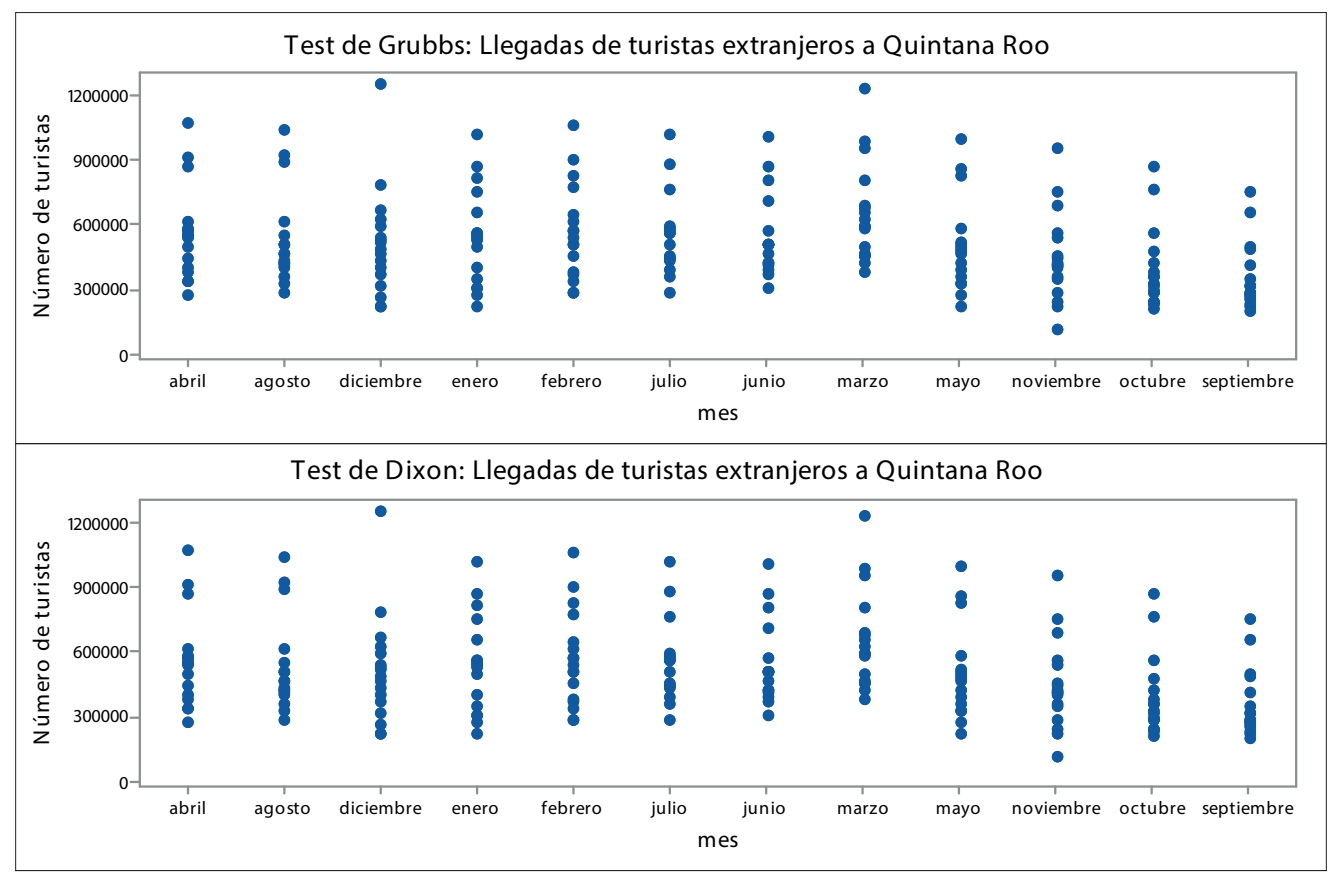

Fuente: Elaboración propia. 
A continuación, la Tabla 3 presenta los resultados en las pruebas de normalidad para las menores cantidades registradas en llegadas de turistas, también en agrupaciones mensuales, descartando que se haya presentado alguna disminución en las visitas de turistas que deban considerarse estadísticamente significativas.

\section{Tabla 3: Identificación de datos atípicos en Impuesto al Hospedaje.} (Prueba a los valores menores)

\begin{tabular}{|l|c|c|l|c|l|}
\hline \multicolumn{1}{|c|}{$\begin{array}{c}\text { Grupos de } \\
\text { datos por mes }\end{array}$} & $\begin{array}{c}\text { Valor mínimo de } \\
\text { la serie } \\
\text { (miles de pesos) }\end{array}$ & $\begin{array}{c}\text { G (Grubbs) } \\
\text { Valor critico } \\
\mathbf{G}<\mathbf{2 . 4 7}\end{array}$ & \multicolumn{1}{|c|}{$\begin{array}{c}\text { Aceptación / rechazo de } \\
\text { hipótesis }\end{array}$} & $\begin{array}{c}\text { Q (Dixon) Valor } \\
\text { crítico } \\
\mathbf{Q}<\mathbf{0 . 3 2 0}\end{array}$ & \multicolumn{1}{|c|}{$\begin{array}{c}\text { Aceptación } \\
\text { /rechazo de } \\
\text { hipótesis }\end{array}$} \\
\hline Enero & 8,646 & 1.10 & Rechazada. No existe dato atípico & 0.01 & $\begin{array}{l}\text { Rechazada. No existe } \\
\text { dato atípico }\end{array}$ \\
\hline Febrero & 9,219 & 1.13 & Rechazada. No existe dato atípico & 0.01 & $\begin{array}{l}\text { Rechazada. No existe } \\
\text { dato atípico }\end{array}$ \\
\hline Marzo & 9,966 & 1.17 & Rechazada. No existe dato atípico & 0.02 & $\begin{array}{l}\text { Rechazada. No existe } \\
\text { dato atípico }\end{array}$ \\
\hline Abril & 12,991 & 1.08 & Rechazada. No existe dato atípico & 0.00 & $\begin{array}{l}\text { Rechazada. No existe } \\
\text { dato atípico }\end{array}$ \\
\hline Mayo & 8,800 & 1.05 & Rechazada. No existe dato atípico & 0.03 & $\begin{array}{l}\text { Rechazada. No existe } \\
\text { dato atípico }\end{array}$ \\
\hline Junio & 5,179 & 1.09 & Rechazada. No existe dato atípico & 0.04 & $\begin{array}{l}\text { Rechazada. No existe } \\
\text { dato atípico }\end{array}$ \\
\hline Julio & 8,358 & 0.99 & Rechazada. No existe dato atípico & 0.00 & $\begin{array}{l}\text { Rechazada. No existe } \\
\text { dato atípico }\end{array}$ \\
\hline Agosto & 10,118 & 1.03 & Rechazada. No existe dato atípico & 0.00 & $\begin{array}{l}\text { Rechazada. No existe } \\
\text { dato atípico }\end{array}$ \\
\hline Septiembre & 9,136 & 0.99 & Rechazada. No existe dato atípico & 0.00 & $\begin{array}{l}\text { Rechazada. No existe } \\
\text { dato atípico }\end{array}$ \\
\hline Octubre & 5,550 & 1.04 & Rechazada. No existe dato atípico & $\begin{array}{l}\text { Rechazada. No existe } \\
\text { dato atípico }\end{array}$ \\
\hline Noviembre & 3,048 & 1.07 & Rechazada. No existe dato atípico & $\begin{array}{l}\text { Rechazada. No existe } \\
\text { dato atípico }\end{array}$ \\
\hline Diciembre & 2,463 & 1.17 & Rechazada. No existe dato atípico & $\begin{array}{l}\text { Rechazada. No existe } \\
\text { dato atípico }\end{array}$ \\
\hline
\end{tabular}

Fuente: Elaboración propia.

Lo anterior puede distinguirse fácilmente mediante el Gráfico 6, presentando todas las observaciones en color azul, es decir, que no se presenta ningún dato que se registró, por pequeño que haya sido, que deba considerarse fuera de lo normal. 
Gráfico 6: Agrupación de valores menores por meses. Impuesto al Hospedaje
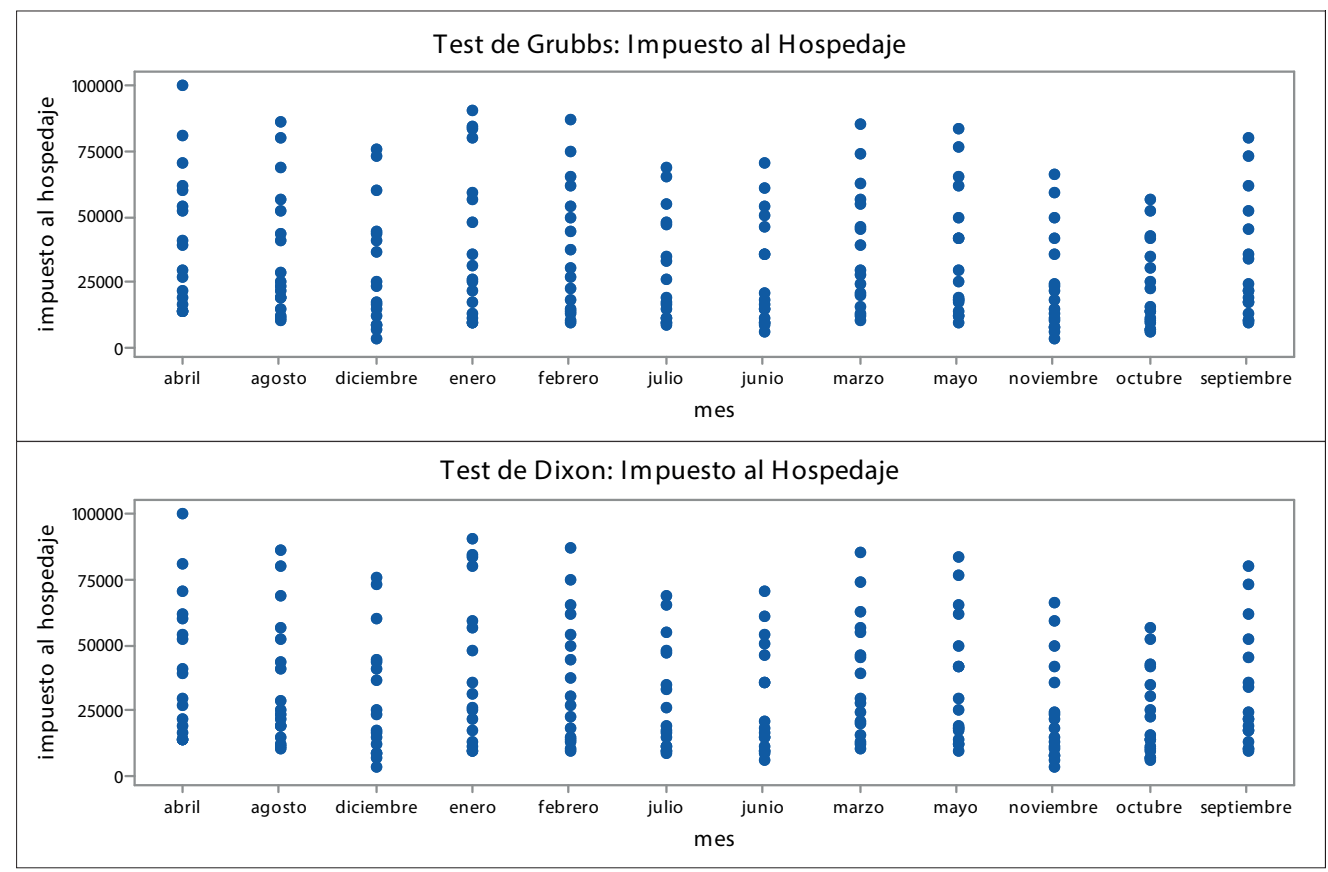

Fuente: Elaboración propia.

Conforme a las mismas agrupaciones mensuales, se realizaron las pruebas (Grubbs y Dixon) para identificar los valores atípicos, pero en esta ocasión se tomaron como referencia los valores más altos de cada mes.

En lo que respecta a los mayores registros de llegadas de turistas en el periodo de 2000 al 2016, las pruebas de normalidad indicaron que en 5 casos (señalados en color amarillo en la Tabla 4), sí pueden ser consideradas disminuciones estadísticamente atípicas, cuatro de estas resultaron así por una de las pruebas de normalidad.

Específicamente el mes de diciembre 2016, resultó fuera de lo normal tanto en la prueba de Grubbs como la de Dixon, las culaes confrmaron que existe una disminución totalmente atípica, es decir que no es comparable con ningún otro período. En apoyo visual a los resultados anteriores se presentan en el Gráfico 7. 
Tabla 4: Identificación de datos atípicos en Llegadas de turistas extranjeros. (Prueba a los valores más grandes)

\begin{tabular}{|l|c|c|l|c|l|}
\hline $\begin{array}{c}\text { Grupos de } \\
\text { datos por } \\
\text { mes }\end{array}$ & $\begin{array}{c}\text { Valor } \\
\text { máximo } \\
\text { de la serie }\end{array}$ & $\begin{array}{c}\text { G (Grubbs) } \\
\text { Valor critico } \\
\mathbf{G}<\mathbf{2 . 4 7}\end{array}$ & \multicolumn{1}{|c|}{$\begin{array}{c}\text { Aceptación / rechazo de } \\
\text { hipótesis }\end{array}$} & $\begin{array}{c}\text { Q } \\
\text { (Dixon) Valor } \\
\text { crítico } \\
\mathbf{Q}<\mathbf{0 . 3 2 0}\end{array}$ & \multicolumn{1}{|c|}{$\begin{array}{c}\text { Aceptación / rechazo de } \\
\text { hipótesis }\end{array}$} \\
\hline Enero & $1,016,911$ & 2.13 & Rechazada. No existe dato atípico & 0.19 & Rechazada. No existe dato atípico \\
\hline Febrero & $1,059,888$ & 2.25 & Rechazada. No existe dato atípico & 0.21 & Rechazada. No existe dato atípico \\
\hline Marzo & $1,224,702$ & 2.51 & $\begin{array}{l}\text { Se acepta. Sí existe dato atípico. } \\
\text { MARZO 2016 }\end{array}$ & 0.29 & Rechazada. No existe dato atípico \\
\hline Abril & $1,060,681$ & 2.37 & Rechazada. No existe dato atípico & 0.20 & Rechazada. No existe dato atípico \\
\hline Mayo & 987,243 & 2.33 & Rechazada. No existe dato atípico & 0.18 & Rechazada. No existe dato atípico \\
\hline Junio & $1,004,001$ & 2.41 & Rechazada. No existe dato atípico & 0.20 & Rechazada. No existe dato atípico \\
\hline Julio & $1,013,806$ & 2.49 & $\begin{array}{l}\text { Se acepta. Sí existe dato atípico. } \\
\text { JULIO 2016 }\end{array}$ & 0.19 & Rechazada. No existe dato atípico \\
\hline Agosto & $1,029,980$ & 2.34 & Rechazada. No existe dato atípico & 0.15 & Rechazada. No existe dato atípico \\
\hline Septiembre & 749,155 & 2.53 & $\begin{array}{l}\text { Se acepta. Sí existe dato atípico. } \\
\text { SEPTIEMBRE 2016 }\end{array}$ & 0.17 & Rechazada. No existe dato atípico \\
\hline Octubre & 857,688 & 2.55 & $\begin{array}{l}\text { Se acepta. Sí existe dato atípico. } \\
\text { OCTUBRE 2016 }\end{array}$ & 0.15 & Rechazada. No existe dato atípico \\
\hline Noviembre & 944,486 & 2.42 & Rechazada. No existe dato atípico & 0.23 & Rechazada. No existe dato atípico \\
\hline Diciembre & $1,242,648$ & 3.00 & $\begin{array}{l}\text { Se acepta. Sí existe dato atípico. } \\
\text { DICIEMBRE 2016 }\end{array}$ & 0.45 & $\begin{array}{l}\text { Se acepta. Sí existe dato atípico. } \\
\text { DICIEMBRE 2016 }\end{array}$ \\
\hline
\end{tabular}

Fuente: Elaboración propia.

Gráfico 7: Agrupación de valores más grandes por meses. Llegadas de turistas extranjeros a Quintana Roo
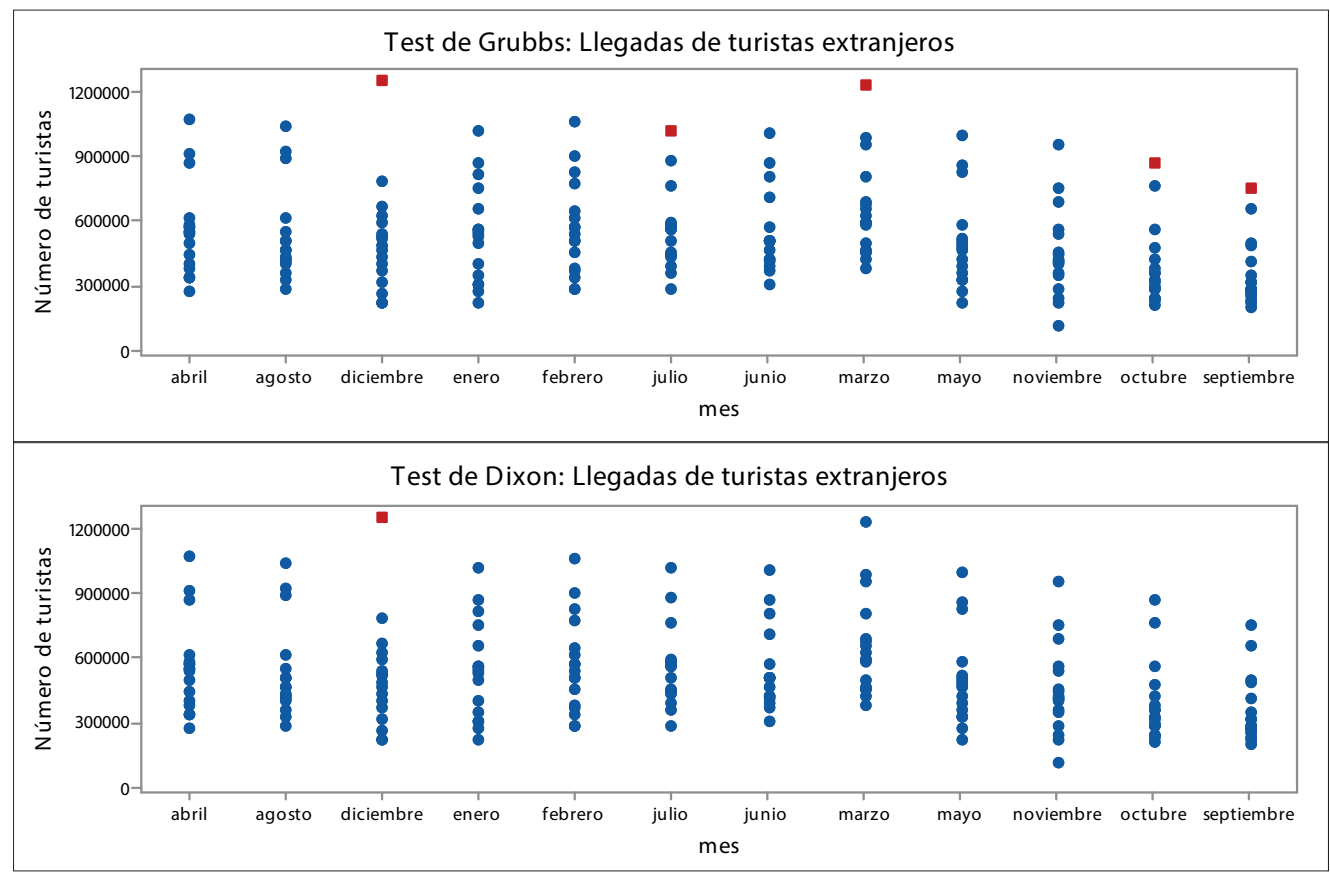

Fuente: Elaboración propia. 
En lo referente a las mayores recaudaciones del impuesto al hospedaje, el Gráfico 8 muestra que en ningún caso se presentó una recaudación mayor que, en correspondencia con las llegadas de turistas pueda considerare estadísticamente fuera de lo normal.

\section{Gráfico 8: Agrupación de valores más grandes por meses Impuesto al Hospedaje}

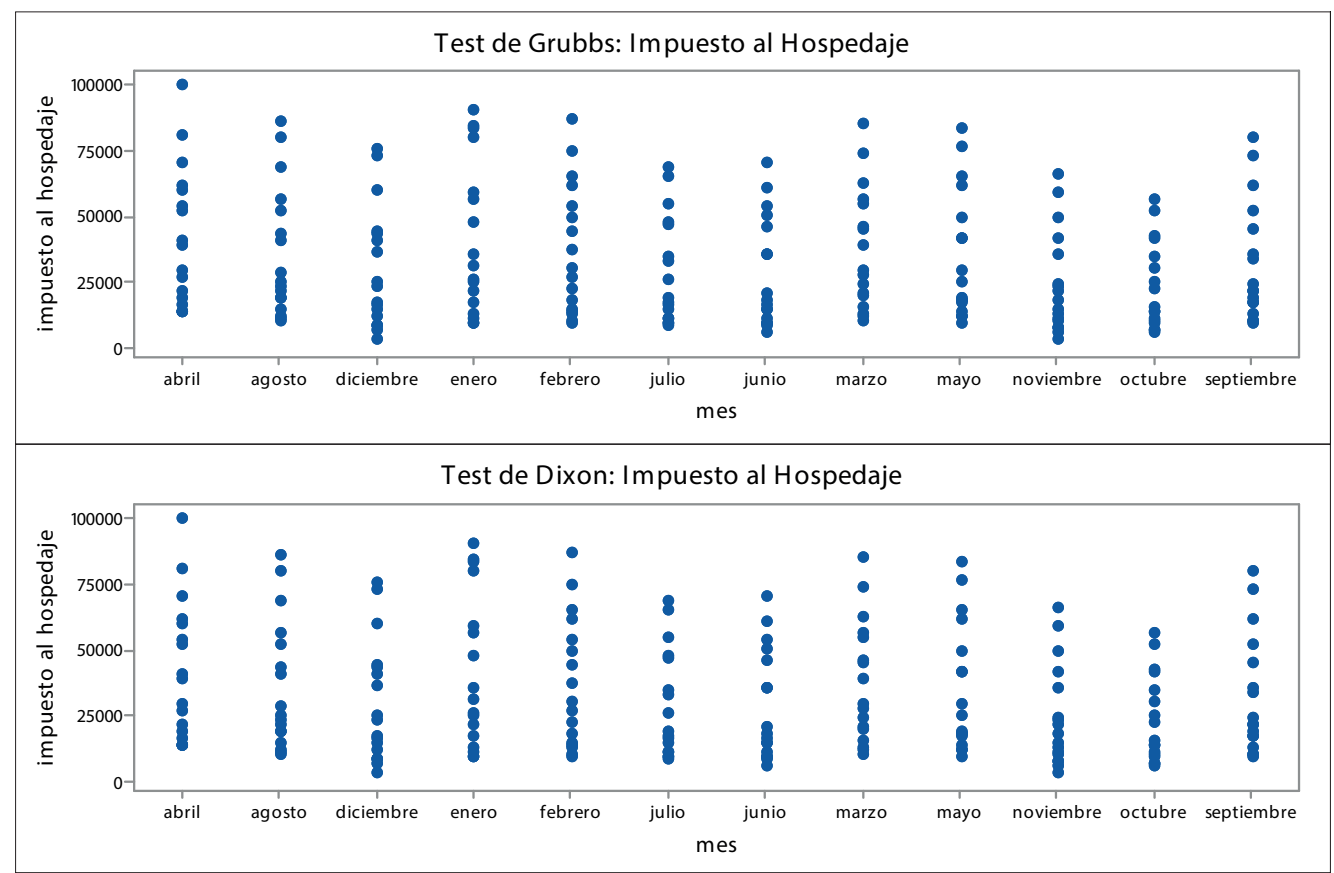

Fuente: Elaboración propia.

Finalmente se aplican los test de Grubbs y Dixon para los valores más grandes en la recaudación fiscal y se confirman con los resultados de la Tabla 5 que, a diferencia de las llegadas de turistas, en el impuesto al hospedaje ningún caso puede considerarse significativo o atípico, situación que deja una gran incógnita para futuras investigaciones, ya que: ¿cómo puede ser posible que aumenten de forma estadísticamente el número de turistas pero no la recaudación? 
Tabla 5: Identificación de datos atípicos en Impuesto al Hospedaje (Prueba a los valores más grandes)

\begin{tabular}{|c|c|c|c|c|c|}
\hline $\begin{array}{l}\text { Grupos de } \\
\text { datos por } \\
\text { mes }\end{array}$ & $\begin{array}{c}\text { Valor máximo de } \\
\text { la serie } \\
\text { (miles de pesos) }\end{array}$ & $\begin{array}{c}\text { G (Grubbs) } \\
\text { Valor critico } \\
G<2.47 \\
\end{array}$ & $\begin{array}{c}\text { Aceptación / rechazo de } \\
\text { hipótesis }\end{array}$ & $\begin{array}{c}Q \text { (Dixon) } \\
\text { Valor crítico } \\
Q<0.320 \\
\end{array}$ & $\begin{array}{l}\text { Aceptación } \\
\text { / rechazo de } \\
\text { hipótesis }\end{array}$ \\
\hline Enero & 89,631 & 1.68 & Rechazada. No existe dato atípico & 0.07 & $\begin{array}{l}\text { Rechazada. No } \\
\text { existe dato atípico }\end{array}$ \\
\hline Febrero & 86,077 & 2.02 & Rechazada. No existe dato atípico & 0.15 & $\begin{array}{l}\text { Rechazada. No } \\
\text { existe dato atípico }\end{array}$ \\
\hline Marzo & 84,468 & 2.07 & Rechazada. No existe dato atípico & 0.15 & $\begin{array}{l}\text { Rechazada. No } \\
\text { existe dato atípico }\end{array}$ \\
\hline Abril & 99,762 & 2.22 & Rechazada. No existe dato atípico & 0.23 & $\begin{array}{l}\text { Rechazada. No } \\
\text { existe dato atípico }\end{array}$ \\
\hline Mayo & 82,793 & 1.99 & Rechazada. No existe dato atípico & 0.09 & $\begin{array}{l}\text { Rechazada. No } \\
\text { existe dato atípico }\end{array}$ \\
\hline Junio & 69,493 & 2.00 & Rechazada. No existe dato atípico & 0.15 & $\begin{array}{l}\text { Rechazada. No } \\
\text { existe dato atípico }\end{array}$ \\
\hline Julio & 68,235 & 1.94 & Rechazada. No existe dato atípico & 0.06 & $\begin{array}{l}\text { Rechazada. No } \\
\text { existe dato atípico }\end{array}$ \\
\hline Agosto & 85,616 & 2.03 & Rechazada. No existe dato atípico & 0.08 & $\begin{array}{l}\text { Rechazada. No } \\
\text { existe dato atípico }\end{array}$ \\
\hline Septiembre & 79,481 & 2.12 & Rechazada. No existe dato atípico & 0.10 & $\begin{array}{l}\text { Rechazada. No } \\
\text { existe dato atípico }\end{array}$ \\
\hline Octubre & 55,993 & 2.00 & Rechazada. No existe dato atípico & 0.10 & $\begin{array}{l}\text { Rechazada. No } \\
\text { existe dato atípico }\end{array}$ \\
\hline Noviembre & 65,458 & 2.15 & Rechazada. No existe dato atípico & 0.11 & $\begin{array}{l}\text { Rechazada. No } \\
\text { existe dato atípico }\end{array}$ \\
\hline Diciembre & 75,278 & 1.99 & Rechazada. No existe dato atípico & 0.04 & $\begin{array}{l}\text { Rechazada. No } \\
\text { existe dato atípico }\end{array}$ \\
\hline
\end{tabular}

Fuente: Elaboración propia.

\section{Conclusiones}

Los resultados obtenidos demuestran que los datos anómalos, es decir con mayores variaciones respecto al patrón de comportamiento en los 17 años analizados resultaron sistemáticamente en las llegadas de turistas, tal es el caso para los meses de marzo, julio, septiembre, octubre y diciembre de 2016, estas condiciones atípicas de acuerdo a los criterios del test de Grubs (G) permiten concluir que en el mes de diciembre resultó anómalo tanto para el test $\mathrm{G}$ como para el test de Dixon (Q).

Es importante señalar que, en 2016, es el único año en que se identifican las anomalías estadísticamente significativas es coincidentemente, el período de cambio de gobierno en el estado de Quintana Roo, momento en el cual concluyó la administración de Roberto Borge Angulo, siendo sucedido por el ahora Gobernador de Quintana Roo, Carlos Joaquín González, quien entró en funciones desde el mes de septiembre del año 2016.

Lo anterior deja muy serias incógnitas que invitan a profundizar en la investigación, la primera en el sentido de indagar las razones del porqué se registraron grandes llegadas de turistas extranjeros, a pesar de que el estado presentaba una sobre carga de deuda pública y en consecuencia escases de recursos públicos que incluirían la promoción; además de no coincidir con algún fenómeno económico mundial o del mercado principal en donde se originan los turistas, ya que se debieron presentar singularidades de tipo económico o de promoción, influyentes y positivos, que su incidencia proporcionalmente superara inclusive los resultados negativos ocasionados por Wilma en 2005 pero en sentido positivo.

La incógnita presentada en el apartado anterior se robustece de sentido, toda vez que la recaudación del impuesto al hospedaje está íntimamente relacionada con las estancias por llegadas de turistas extranjeros al destino, tal como lo ha demostrado por el Primer Lugar del Premio Nacional de Investigación Impulso al Desarrollo de las Finanzas Estatales (Lagunas, 2015), el cual precisa que dadas las actividades turísticas, del total de impuestos de recaudación directa del estado (más del 35\%) depende del impuesto al hospedaje, entonces ¿cómo se explica haber recibido más turistas y no incrementos significativos en la recaudación fiscal? 
La segunda incógnita que genera expectativa y estímulo para el desarrollo de nuevas investigaciones, es en el sentido de verificar los registros estadísticos en las llegadas de los turistas, ya que pudieron suscitarse dos situaciones, la primera que durante 17 años hubiese existido un "sub registro" en los datos, ya sea por una incorrecta metodología o en la gestión en los datos, lo que llevó a un nuevo gobierno a encontrar la forma correcta de registrar las llegadas al destino, en todo caso, estos registros, junto con los que correspondan a otras variables de las visitas, sin lugar a dudas influyeron o incluso incidirán en el ranking del estado o país.

\section{Bibliografía}

Ang, A. \& Willson, T. 2007. Probability Concepts in Engineering. Emphasis on Applications on Civil anD Eviromental Engineering. usa: Johm Wiley and Sons, Inc .

Beck, G. \& Grubbs, F. 1972. Extension of Sample Sizes and Percentage Points for Significance Tests of Outlying Observations. Technometrics, Vol. 14, No. 4, 847-854.

Böhrer, A. 2008. One-sided and Two-sided Critical Values for Dixon's Outlier Test for Sample Sizes up to $\mathrm{n}=30$. Economic Quality Control, 23(1), 5-13. Economic Quality Control, 23(1) , 5-13.

Cañada, E. 2017. El turismo como catalizador de la pobreza. Trabajo turístico y precariedad en Cozumel, México. Barcelona: Alba Sud.

Cárdenas, E. 1996. La política económica en México, 1950 - 1994. México: Fondo de Cultura Económica.

Centro de Estudios de las Finanzas Públicas (2009). El impacto de la contingencia sanitaria por el Virus de Influenza Humana en el Sector Turismo en México al segundo trimestre del 2009. México: Congreso de la Unión.

CEPAL 2010. Evaluación preliminar del impacto en México de la influenza AH1N1: documento elaborado por el equipo conjunto CEPAL. México: Comisión Económica para América Latina y el Caribe.

Congreso del Estado 2015. Ley de Ingresos del estado de Quintana Roo para el Ejercicio Fiscal 2016. Chetumal: Congreso del Estado.

Dan, E. \& Ijeima, O. 2013. Statistical analysis/methods of detecting outliers in a univariate data in a regression analysis model. International Journal of Education and Research Vol. 1 No. 5 , 1-24.

Dixon, J. 1951. Ratios involving extreme values. Journal of the American Statistical Association, Vol. 48, No. $263,68-78$.

Grubbs, F. 1969. Procedures for Detecting Outlying Observations in Samples. Technometrics Vol. 11, No. 1, 1-21.

Holden, A. 2006. Tourism Studies and the Social Sciences. New York: Routledge.

Jarmin, R. \& Miranda, J. 2009. The Impact of Hurricanes Katrina, Rita and Wilma on Business Establishments. Journal of Business Valuation and Economic Loss Analysis, 4, issue 2, 1-29.

Jiménez, A. 1993. Turismo, estructura y desarrollo. México: McGraw Hill.

Lagunas, S. 2015. Análisis fractal aplicado a la recaudación local como medida de control para las finanzas estatales. In Investigaciones Ganadoras. Premio Nacional de INvestigación „Impulso al Desarrollo de las Finanzas Estatales“(pp. 1-41). México: UNAM.

Lagunas, S. \& Cervantes, C. 2019. Expectativas para que México cambie el destino de sus exportaciones. Revista de Métodos Cuantitativos para la Economía y la Empresa, 3-22.

Macedo, R. 1995. Análisis del modelo turístico mexicano en el sexenio 1989-1994 desde un ámbito macroeconómico. México: Universidad Nacional Autónoma del Estado de México.

Mansilla, E. 2006. Katrina, Stan y Wilma: tres desastres en busca de un paradigma. Nueva Sociedad, (201), 11-19.

OMT 2017. Panorama OMT del turismo internacional. Edición 2017. Madrid: Organización Mundial del Turismo.

OMT 2019. International arrivals grew 4\% in the first quarter of 2019. Tourism Barometer, 17 (2): 1-4.

Oswald, S. 2012. Vulnerabilidad sociel en eventos hodrometeorológicos extremos: una comparación entre los huracanes Stan y Wilma en México. Revista Internacional de Ciencias Sociales y Humanidades, SOCIOTAM, XII (2) , 125-146.

Palafox-Muñoz, A. 2013. El turismo como eje de acumulación. Nómadas, Número Especial América Latina, 161-174.

Palafox, A. \& Alvarado, A. 2005. La promoción del turismo en México: repitiendo esquemas. México: Plaza y Valdés - Universidad de Quintana Roo.

Palafox, A. \& Velázquez, A. 2008. Impacto económico originado por el huracán Wilma en el empleo turístico de la isla de Cozumel. México: Plaza y Valdés Editores - Universidad de Quintana Roo. 
Sánchez, G. 2006. Huracanes de 2005 y 2005 y su Impacto en el Sector Asegurador Mexicano. México: Comisión Nacional de Seguros y Fianzas.

Secretaría de Finanzas y Planeación 2016b. Norma para Establecer la Estructura del Calendario de Ingresos Base Mensual 2016. Chetumal: Secretaría de Finanzas y Planeación.

Secretaría de Finanzas y Planeación de Quintana Roo 2016a. Respuesta 37016 a solicitud de información pública gubernamental. Procuraduría Fiscal del Estado. Chetumal: Secretaría de Finanzas.

Secretaria de Gobernación 22 de 01 de 2013. Decreto por el que se establece el Sistema Nacional para la Cruzada contra el Hambre. Diario Oficial de la Federación .

SECTUR 2019. Resultados de la actividad turística 2018. Ciudad de México: Secretaría de Turismo.

SECTUR 23 de 03 de 2018. Datatur. Información Turística por Entidad Federativa - Quintana Roo. From Lllegadas mensuales de turistas a la entidad: http://www.datatur.sectur.gob.mx/ITxEF/ITxEF_QROO.aspx

SEDETUR 2008. Indicadores turísticos del estado de Quintana Roo 2008. Chetumal: SEDETUR - Gobierno del Estado de Quintana Roo.

SETUR 2017. Diagnóstico Mesa 2. Recaudación y administración de recursos par alos destinos turísticos. Mérida: Secrearía de Turismo.

Siekelova, A., Kliestik, T., Svabova, L., Androniceanu, A. \& Schonfeld, J. 2017. Receivables management: the importance of financial indicators in assessing the creditworthiness. Polish Journal of Management Studies, Vol.15 Núm.2, 217-228.

Solak, M. K. 2009. Detection of multiple outliers in univariate data sets. USA: Paper SP06-2009, Schering.

Stephens, M. 1979. The Anderson-Darling Statistic. Technical Report Num. 39. USA: Department of Statistics, Stanford University.

Unión Cancún 2016. Huracán Wilma el desastre más caro de México: 1,752 mdd. México: Unión Cancún Quintana Roo.

Urvoy, M. \& Autrusseau, F. 2014. Application of Grubbs' test for outliers to the detection of watermarks. In Proceedings of the 2nd ACM workshop on Information hiding and multimedia security , 49-60.

WTTC 2017. Economic impact 2017. London: Economic impact 2017. Wordl Travel \& Tourism Council.

\section{Notas}

\footnotetext{
Se consideran los informes de la recaudación mensual 2000 a 2015 obtenidos mediante solicitud de transparencia (Secretaría de Finanzas y Planeación, 2006a); para la recaudación del 2016 se considera el informe denominado "Norma para Establecer la Estructura del Calendario de Ingresos Base Mensual", obteniendo la recaudación del hospedaje como resultado de aplicar el factor de 0.8647 al total de ingresos mensuales sobre producción, consumo y transacciones, en donde se agrupa el impuesto al hospedaje (Secretaría de Finanzas y Planeación, 2006b). Dicho factor se obtiene a partir de las cifras de la Ley de Ingresos del estado de Quintana Roo para el ejercicio fiscal 2016 (Congreso del Estado, 2015).
} 